\title{
Neurochemical Characterization and Sexual Dimorphism of Projections from the Brain to Abdominal and Subcutaneous White Adipose Tissue in the Rat
}

\author{
Elaine S. Adler, ${ }^{1}$ Jacob H. Hollis, ${ }^{1}$ Iain J. Clarke, ${ }^{1}$ David R. Grattan, ${ }^{2}$ and Brian J. Oldfield ${ }^{1}$ \\ ${ }^{1}$ Department of Physiology, Monash University, Clayton 3800, Victoria, Australia, and ${ }^{2}$ Centre for Neuroendocrinology and Department of Anatomy, \\ University of Otago, Dunedin 9054, New Zealand
}

\begin{abstract}
Retroperitoneal white adipose tissue (rWAT) and subcutaneous (inguinal) white adipose tissue (iWAT) are both innervated and regulated by sympathetic efferents, but the distribution and identity of the cells in the brain that regulate sympathetic outflow are poorly characterized. Our aim was to use two isogenic strains of a neurotropic virus (pseudorabies, Bartha) tagged with either green or red fluorescent reporters to identify cells in the brain that project to rWAT and/or iWAT. These viruses were injected into separate WAT depots in male and female Sprague Dawley rats. Retrogradely labeled neurons in the CNS were characterized by immunohistochemistry and PCR. For the latter, laser capture of individual virally labeled neurons was used. All virally labeled brain regions contained neurons projecting to either and both WAT depots. Neurons to abdominal fat were the most abundant in males, whereas females contained a greater proportion of neurons to subcutaneous via private lines and collateral branches. Retrogradely labeled neurons directed to WAT expressed estrogen receptor- $\alpha(\mathrm{ER} \alpha)$, and fewer neurons to subcutaneous WAT expressed ER $\alpha$ in males. Regardless of sex, projections from the arcuate nucleus were predominantly from pro-opiomelanocortin cells, with a notable lack of projections from agouti-related protein-expressing neurons. Within the lateral hypothalamus, neurons directed to rWAT and iWAT expressed orexin and melaninconcentrating hormone $(\mathrm{MCH})$, but male rats had a predominance of $\mathrm{MCH}$ directed to iWAT. In conclusion, the neurochemical substrates that project through polysynaptic pathways to iWAT and rWAT are different in male and female rats, suggesting that metabolic regulation of rWAT and iWAT is sexually dimorphic.
\end{abstract}

\section{Introduction}

A sexual dimorphism exists with respect to white adipose tissue (WAT) deposition. Males have more abdominal WAT, and females have greater subcutaneous WAT depots (Kotani et al., 1994; Gambacciani et al., 2001; Tchernof et al., 2004; Clegg et al., 2006). Pathological sequelae of obesity are more significantly related to the amount of abdominal WAT, whereas subcutaneous WAT is relatively benign (Park et al., 2003). These sex differences prompt a need to understand the potential of the nervous system to regulate lipolysis in the different fat compartments in both sexes. Bartness et al. (1989) found that male Siberian hamsters shed body fat when transitioned from long to short-day photoperiod, and did so disproportionately such that the greatest loss was from abdominal fat depots. Furthermore, noradrenaline turnover was greater in abdominal fat in animals undergoing this

Received May 30, 2012; revised Aug. 5, 2012; accepted Aug. 20, 2012.

Author contributions: E.S.A., J.H.H., D.R.G., and B.J.O. designed research; E.S.A. performed research; E.S.A., J.H.H., I.J.C., and B.J.O. analyzed data; E.S.A., J.H.H., I.J.C., D.R.G., and B.J.O. wrote the paper.

This work was supported by National Health and Medical Research Council (NHMRC) Project Grant APP1010318 (B.J.O., I.J.C.). E.S.A. was supported by a Dowd Foundation research scholarship and NHMRC postgraduate research scholarship.

The authors declare no competing financial interests.

Correspondence should be addressed to Professor Brian J. Oldfield, Building 13F, Physiology Department, Monash University, Clayton 3800, VIC, Australia. E-mail: brian.oldfield@monash.edu.

DOI:10.1523/JNEUROSCI.2591-12.2012

Copyright $\odot 2012$ the authors $\quad 0270-6474 / 12 / 3215913-09 \$ 15.00 / 0$ transition, implying a role for the sympathetic nervous system. (Youngstrom and Bartness, 1995). The notion that differential innervation of fat determines the relative size of the two major fat compartments is supported by the fact that small quantities of estradiol injected into the cerebral ventricles of overiectomized rats caused a redistribution of fat, possibly through a differential lipolytic effect (Clegg et al., 2006). These functional responses could be determined by specificity in the polysynaptic pathways from the brain to the different fat depots (Bamshad et al., 1998; Kreier et al., 2006). In other words, the CNS pathways involved may be different for different fat beds and may have differing levels of expression of the relevant estrogen receptors (ERs). Accordingly, a more thorough understanding of the brain projections to different fat depots is required in the different sexes.

While specific neuropeptides involved in the mediation of energy balance have been implicated in changes in sympathetic activity to WAT and drive alterations in lipid metabolism, the neurochemical characterization of central projections to specific fat depots remains rudimentary (Billington et al., 1991; Tritos and Maratos-Flier, 1999; Ludwig et al., 2001; Shi and Bartness, 2001; Raposinho et al., 2003; Bartness and Song, 2007; Brito et al., 2007; Tsuneki et al., 2010). In particular, it is important to know which CNS neurons project polysynaptically to the different fat depots and whether these neurons contain sex steroid receptors that might explain, in part, the sexual dimorphism in control of WAT deposition. 
Polysynaptic projections from the brain to distinct WAT depots can be identified using retrograde transynaptic tracing of pseudorabies viruses (PRVs). In this study, we used two isogenic strains of the Bartha strain of PRV (PRV152 or PRV614) (Banfield et al., 2003), which were injected into the subcutaneous and abdominal fat depots of male and female rats. Different (red and green) fluorescent reporters associated with these viruses enables the identification of neurons at each synaptic relay that project through polysynaptic connections to either or both fat depots. In conjunction with immunohistochemistry and single-cell laser capture PCR, valuable insights into the neurochemical signature of these pathways were obtained.

\section{Materials and Methods}

Animals and housing. Male and female Sprague Dawley rats were obtained from the Animal Resource Centre (Canning Vale, WA, Australia) and Monash Animal Services (Clayton, VIC, Australia). Rats (12-16 weeks old) were housed in groups of two to four in standard housing with an ambient room temperature of $22 \pm 1^{\circ} \mathrm{C}$ and a $12 \mathrm{~h}$ light/dark cycle, and were provided ad libitum access to water and standard laboratory chow (GR2; Ridley Agriproducts). All experimental procedures were performed in a biocontainment PC3 facility under regulation by the Australian Quarantine and Inspection Service and were approved by the Monash University School of Biomedical Science Animal Ethics Committee.

Pseudorabies virus injections. Rats were anesthetized using isoflurane (2-3\%) mixed with oxygen. Fat depots were then injected with two isogenic strains of the Bartha strain of pseudorabies with different fluorescent reporters (green PRV152 or red PRV614, both kindly provided by G. Pickard, Colorado State University, Fort Collins, CO) (Smith et al., 2000; Banfield et al., 2003). Specifically, the inguinal (subcutaneous) and retroperitoneal (abdominal) WAT depots were injected with a series of small injections totaling $10 \mu$ l each of PRV614 (red) and PRV152 (green; $10^{8} \mathrm{PFU} / \mathrm{ml}$ ), respectively, with a Hamilton syringe. Each WAT depot was then blotted with a sterile cloth to minimize viral leakage, the wounds of the rats were sutured, and rats were injected with $100 \mu \mathrm{l}$ of Metacam (meloxicam $1 \mathrm{mg} / \mathrm{ml}$, s.c.) to reduce postoperative pain and inflammation. The particular depot into which each virus was injected was reversed in a number of rats to control for potential depot-specific differences in viral uptake. Rats were returned to their home cages for $3 \mathrm{~d}$ to allow for viral transport to the spinal cord, $4 \mathrm{~d}$ for transport to the hindbrain and forebrain, or $5 \mathrm{~d}$ for transport to higher-order neurons in the hindbrain and forebrain. A separate group of rats, to be used for colocalization studies with $\mathrm{ER} \alpha$, melanocortin-concentrating hormone $(\mathrm{MCH})$, and orexin-A (ORX), was injected in a single depot with $10 \mu \mathrm{l}$ of PRV152 or PRV614 and allowed to survive for $5 \mathrm{~d}$ after inoculation.

Intracerebroventricular colchicine injections. To increase the immunostaining sensitivity for certain hypothalamic neuropeptides [agoutirelated protein (AgRP); $\gamma$-melanocyte-stimulating hormone $(\gamma$-MSH), due to the nonspecificity of $\alpha$-MSH antibodies], a cohort of rats that received PRV injections into both WAT depots were also injected intracerebroventrically with $3 \mu \mathrm{l}$ colchicine $(4 \mu \mathrm{g} / \mu \mathrm{l}$ in sterile saline; catalog \#C9754, Sigma-Aldrich) using a $10 \mu$ l Hamilton syringe $\sim 16$ h before perfusion.

Tissue collection. Rats were deeply anesthetized with an injection of pentobarbitone sodium $(100 \mathrm{mg} / \mathrm{kg}$, i.p. $)$ and then perfused transcardially using $100 \mathrm{ml}$ of $0.05 \mathrm{M} \mathrm{PBS}$ and $300 \mathrm{ml}$ of $4 \%$ paraformaldehyde in 0.1 $\mathrm{M}$ phosphate buffer (PB). The brain and spinal cord of each rat were removed.

Immunohistochemical staining procedures. Tissue for immunohistochemistry was postfixed for $12-18 \mathrm{~h}$ and stored in PB containing 30\% sucrose for up to $7 \mathrm{~d}$ at $4^{\circ} \mathrm{C}$. The brains were sectioned at $35 \mu \mathrm{m}$ in the coronal plane, and spinal cord segments were sectioned at $40 \mu \mathrm{m}$ in the horizontal plane using a cyrostat. Tissue sections were collected in a series of four and stored in cryoprotectant (20\% glycerol and 30\% ethylene glycol in PB) at $-20^{\circ} \mathrm{C}$ until used. Sections from rats injected with PRV into both WAT depots were mounted and coverslipped using fluorescent
Table 1. Names, sequences, and GenBank accession numbers for the forward and reverse primers used for gene expression analysis of MC4R, $0 \mathrm{bRb}$, insulin receptors, ER $\alpha, E R \beta, N P Y, C A R T$, and $18 S$

\begin{tabular}{lll}
\hline Primer name & Primer Sequence & GenBank accession number \\
\hline MC4R F1 & ACTCAGACGGAGGATGCTATG & U67863 \\
MC4R R1 & AGGGTGATGACGATGGTTTC & \\
MC4R F2 & GGTGTTTGTGACTCTGGGTGT & \\
MC4R R2 & ATGGGTGAGTGCAGGTTC & \\
ObRb F1 & GGGCAGAATCAGCACACA & U60151 \\
ObRb R1 & GCCACTTCATTCCATCATCA & \\
ObRb F2 & GCCCATGAGTAAAGTGAA & \\
ObRb R2 & GTGACAGTGTCCAGGAAAGG & \\
Insulin receptor F1 & TTTCCCAACATCTCCTCCAC & NM_017071 \\
Insulin receptor R1 & ACGATGTCATCTGCCTTAGC & \\
Insulin receptor F2 & CGAAGAGCACAGACCATTTG & \\
Insulin receptor R2 & TGCGGTACCCAGTGAAGT & \\
ER $\alpha$ F1 & TGGAGATCCTGATGATTGGTC & NM_012689 \\
ER $\alpha$ R1 & TGATTGATTTGAGGCACACA & \\
ER $\alpha$ F2 & TTGCTCTTGGACAGGAATCA & \\
ER $\alpha$ R2 & TCATGCGGAATGGACTTG & \\
ER $\beta$ F1 & AGGTGCTAATGGTGGACTG & NM_012754 \\
ER $\beta$ R1 & ACTTTCTGCTCCTGGTTG & \\
ER $\beta$ F2 & GGAAGTGCGTAGAAGGGATT & \\
ER $\beta$ R2 & CATGGCCTTCACACAGAGAT & \\
NPYF1 & GTGTGTTTGGGCATTCTGG & NM_012614 \\
NPY R1 & GGGTCTTCAAGCCTTGTTCT & \\
NPYF2 & GCTCTGCGACACTACATCAAT & \\
NPY R2 & GTCTCAGGGCTGGATCTCTT & \\
CART F1 & GCTGCTGCTACCTTTGCTG & U10071 \\
CART R1 & TCGGAATGCGTTTACTCTTG & \\
\hline
\end{tabular}

mounting medium (DAKO) for microscopic investigation of PRV localization.

Sections from rats injected with PRV into a single WAT depot only were used for immunofluorescent colocalization with ER $\alpha$ ( 15 females; 11 males), MCH (6 females; 8 males), or ORX (6 females; 8 males). Sections from rats injected with PRV into both WAT depots and also treated with colchicine were used for immunofluorescent colocalization with AgRP or $\gamma$-MSH ( 3 females; 4 males). Brain sections were immunostained using free-floating immunohistochemistry procedures. The primary antibodies used were polyclonal rabbit anti-ER $\alpha$ antibody (C1355; 1:24,000; catalog \#06-935, Millipore), goat anti-MCH (1:500; catalog \#SC-14509, Santa Cruz Biotechnology), goat anti-orexin-A (1: 1000; catalog \#SC-8070, Santa Cruz Biotechnology), polyclonal guineapig anti-AgRP antibody (1:500; catalog \#GPAAGRP.1, Antibodies Australia), and polyclonal guinea pig anti- $\gamma$-MSH (1:250; catalog \#GPAGMSH.1, Antibodies Australia). Secondary antibodies used were FITC-conjugated donkey anti-rabbit antibody (1:500; catalog \#A-21206, Invitrogen), FITC-conjugated donkey anti-goat antibody (1:500; catalog \#705-095-147, Jackson ImmunoResearch), and aminomethylcoumarin acetate-conjugated donkey anti-guinea pig antibody (1:500; catalog \#706-155-148, Jackson ImmunoResearch).

Tissue sections underwent three 10 min washes in $\mathrm{PB}$ before blocking for 30 min in 10\% normal horse serum (NHS) in PB containing $0.3 \%$ Triton X-100. Tissue was then incubated in primary antibodies at $4^{\circ} \mathrm{C}$ for $48 \mathrm{~h}$ for $\mathrm{ER} \alpha$ staining or at room temperature for $24 \mathrm{~h}$ for all other antibodies. After incubation, the tissue was washed once in PB containing $0.3 \%$ Triton X-100 with $1 \%$ NHS and twice in PB with $1 \%$ NHS, and then incubated with the respective secondary antibody for $90 \mathrm{~min}$. Finally, the tissue was washed in PB twice for $15 \mathrm{~min}$. All immunostained tissue sections were then mounted and coverslipped using a fluorescent mounting medium (DAKO).

Immunohistochemical analysis. Before any counts of PRV-positive neurons, rats were ranked according to the degree of infection, whereby overinfected rats [ $>550$ PRV-positive neurons across three sections of the medial preoptic nucleus (MPO); $5 \%$ of animals injected] and underinfected rats $(<20 \mathrm{PRV}$-positive neurons across three sections of the 
A

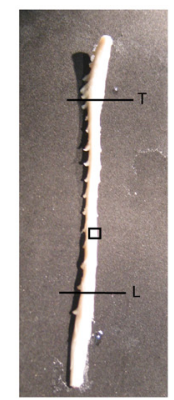

C

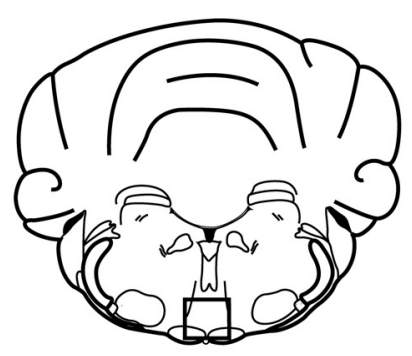

Bregma -10.52

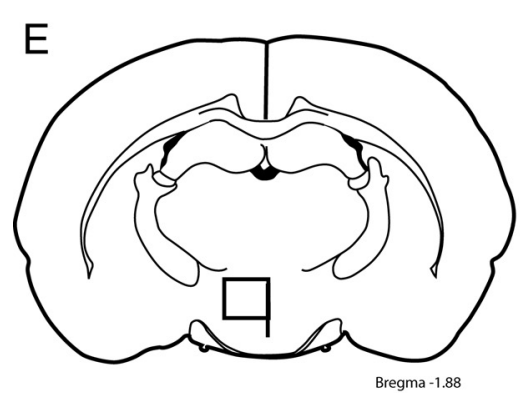

$\mathrm{G}$

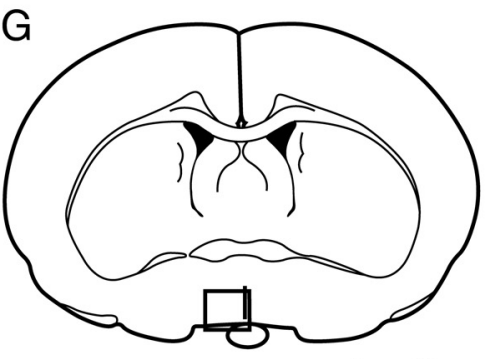

Bregma -0.26
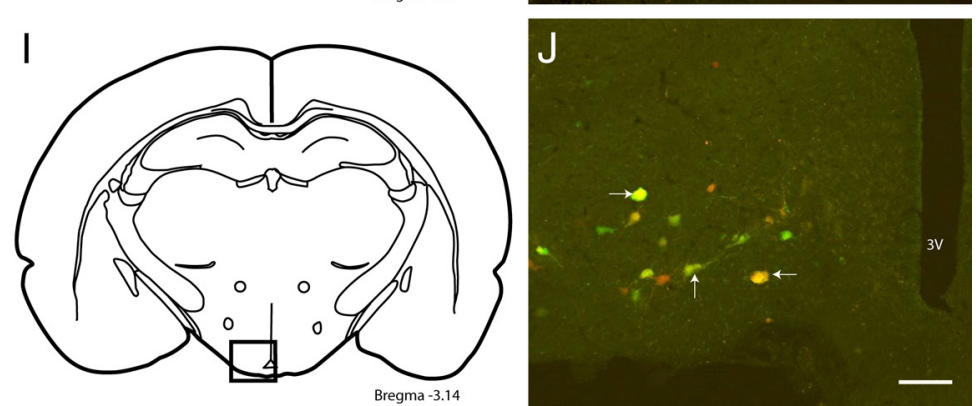

Figure 1. Photograph $(\boldsymbol{A})$ and schematics $(\boldsymbol{C}, \boldsymbol{E}, \boldsymbol{G}, \boldsymbol{I})$ (adapted from Paxinos and Watson (1998) illustrate the areas (boxed regions) and bregma levels shown in the photomicrographs on the right. $\boldsymbol{B}, \boldsymbol{D}, \boldsymbol{F}, \boldsymbol{H}, \boldsymbol{J}$, Photomicrographs of neurons projecting polysynaptically to abdominal (green), subcutaneous (red), and both (yellow; white arrows) WAT depots in the spinal cord $(\boldsymbol{B}$; between T8 and T10), raphe magnus $(\boldsymbol{D})$, paraventricular nucleus $(\boldsymbol{F})$, medial preoptic region $(\boldsymbol{H})$, and arcuate nucleus $(\boldsymbol{J})$ of rats allowed to survive for $3 \mathrm{~d}(\boldsymbol{B})$ or $5 \mathrm{~d}(\boldsymbol{D}, \boldsymbol{F}, \boldsymbol{H}, \boldsymbol{J}) .3 \mathrm{~V}$, Third ventricle; gm, gray matter; L, lumbar segment of the spinal cord; $0 x$, optic chiasm; py, pyramidal tract; $T$, thoracic segment of the spinal cord; wm, white matter. Scale bars: $100 \mu \mathrm{m}$.
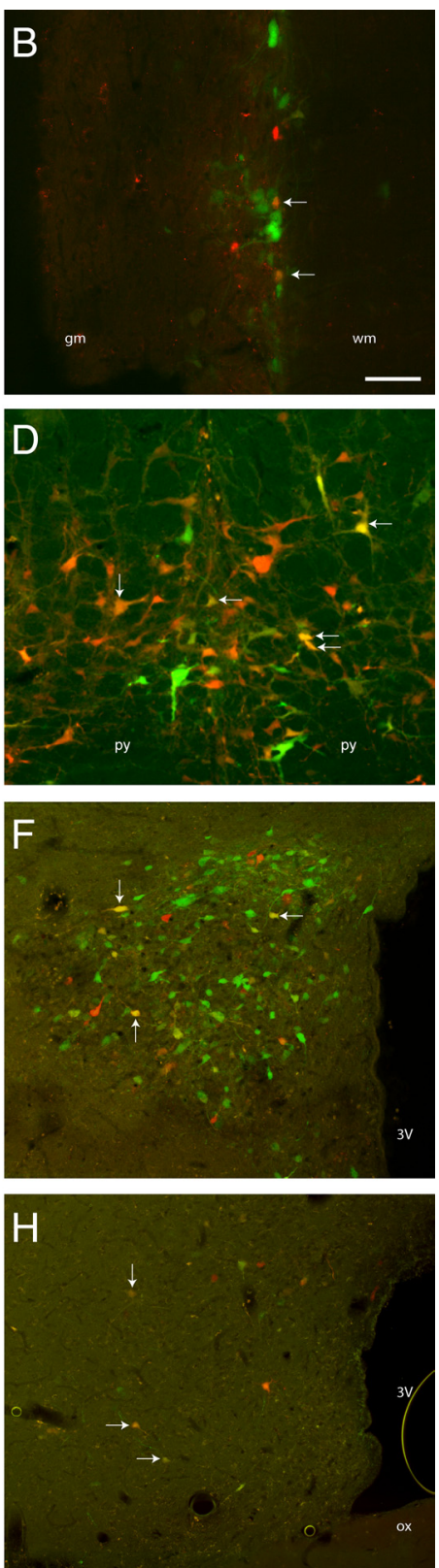

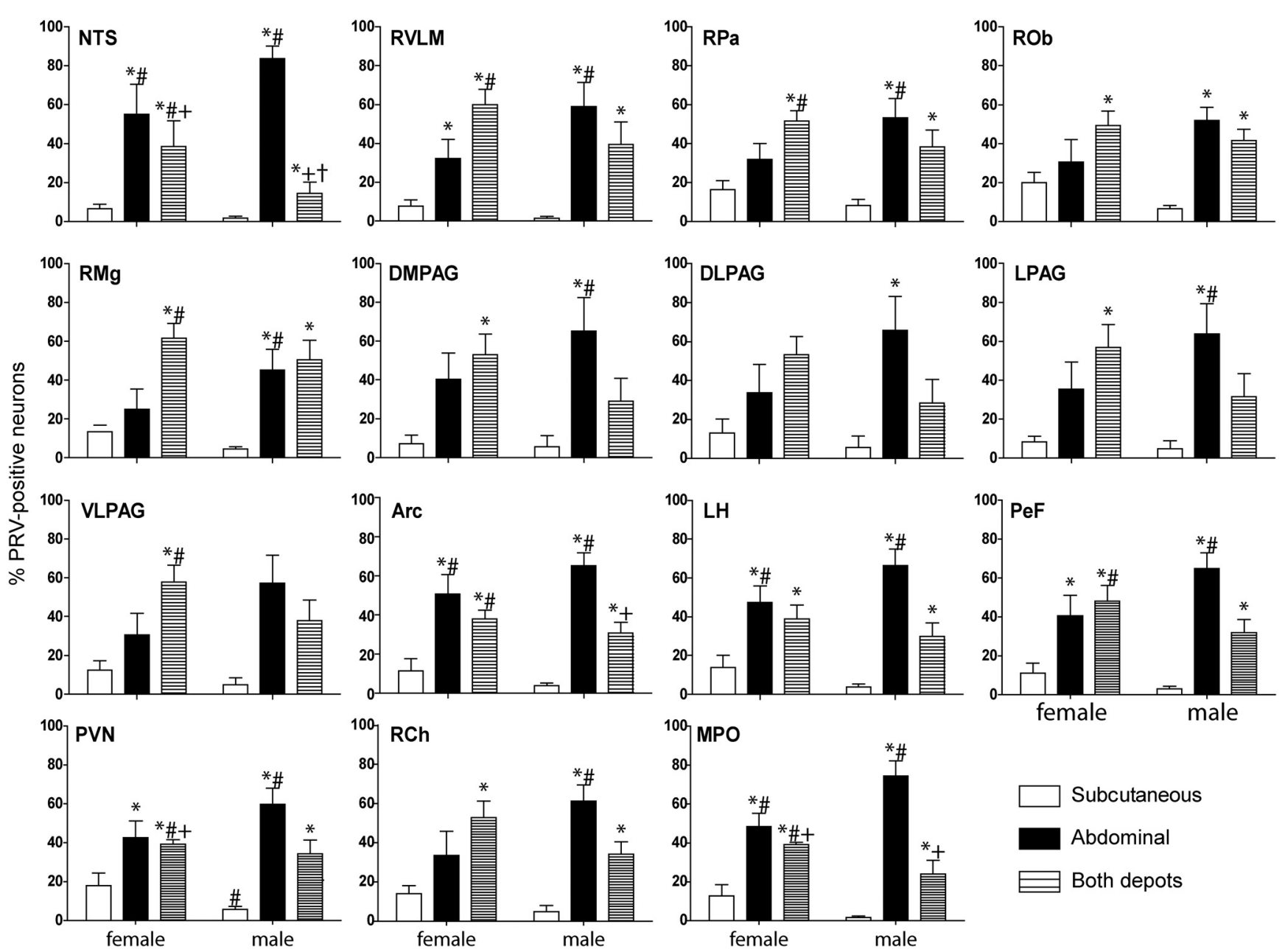

Figure 2. The relative proportion of neurons projecting to abdominal, subcutaneous, and both fat depots in the forebrain and hindbrain of both male $(n=5)$ and female $(n=4)$ rats injected into the right retroperitoneal and inguinal WAT and allowed to survive for $5 \mathrm{~d}$. Both depots, Neurons projecting to both fat depots; DLPAG, dorsolateral PAG; DMPAG, dorsomedial PAG; LPAG, lateral PAG; VLPAG, ventrolateral PAG. ${ }^{*} p<0.05$ compared to male neurons projecting to the subcutaneous fat depot; ${ }^{\#} p<0.05$ compared to female neurons projecting to the subcutaneous fat depot; ${ }^{+} p<0.05$ compared to male neurons projecting to the abdominal fat depot; ${ }^{\dagger} p<0.05$ compared to female neurons projecting to the abdominal fat depot.

amphetamine-regulated transcript (CART), neuropeptide $Y(N P Y)$, long form of the leptin receptor $(\mathrm{ObRb})$, insulin receptor (IR), $E R \alpha, E R \beta$, and melanocortin-4 receptor (MC4R); for sequences, see Table 1] using a GoTaq kit (Promega). First round amplification using a Mastercycler was performed in $0.5 \mathrm{ml} \mathrm{PCR}$ tubes: $95^{\circ} \mathrm{C}(5 \mathrm{~min}) ; 36$ cycles of $95^{\circ} \mathrm{C}(1$ $\mathrm{min}), 48.3^{\circ} \mathrm{C}(1.5 \mathrm{~min})$, and $72^{\circ} \mathrm{C}(1.5 \mathrm{~min})$; and $72^{\circ} \mathrm{C}(5 \mathrm{~min})$ to polish the DNA termini. Second-round nested PCR was performed using $1 \mu$ lof first-round amplicon pool and 0.8 pmol of the appropriate nested oligonucleotide F2 and R2 primers (for sequences, see Table 1 ) in a 25 $\mu \mathrm{l}$ reaction using the same GoTaq kit. Amplification was performed as described previously except that annealing was performed at $56^{\circ} \mathrm{C}$ for $\mathrm{ObRb}, 52.6^{\circ} \mathrm{C}$ for $M C 4 R, 48.3^{\circ} \mathrm{C}$ for insulin receptor and NPY, $45.1^{\circ} \mathrm{C}$ for $E R \alpha$ and $C A R T$, and $46.5^{\circ} \mathrm{C}$ for $E R \beta$, and extension for all primer pairs was performed at $72^{\circ} \mathrm{C}(35 \mathrm{~s})$.

As a control, a $50 \mu \mathrm{l}$ reaction PCR for $18 S$ was performed using RT product, 0.1 pmol each of oligonucleotide $18 S$ forward and reverse primers and the same GoTaq kit. Amplification was performed in $0.2 \mathrm{ml} \mathrm{PCR}$ tubes: $95^{\circ} \mathrm{C}(5 \mathrm{~min}) ; 51$ cycles of $95^{\circ} \mathrm{C}(1 \mathrm{~min}), 58^{\circ} \mathrm{C}(1.5 \mathrm{~min})$, and $72^{\circ} \mathrm{C}$ ( $1.5 \mathrm{~min})$; and $72^{\circ} \mathrm{C}(5 \mathrm{~min})$ to polish the DNA termini. Water was used in place of template as a negative control, and cDNA from a whole rat hypothalamus was used as a positive control for all transcripts. Primers for $O b R b$, insulin receptor, $E R \alpha, E R \beta, N P Y$, and $C A R T$ were intron spanning and could be used to detect the presence of contaminating genomic DNA. Examination of first-round products was not performed on a regular basis, but in preliminary experiments developing the methodology, one band $\sim 200$ bp in length was usually detected.
The resulting amplicons (CART, $102 b p ; N P Y, 65 b p$; ObRb, $86 b p$; insulin receptor, $83 \mathrm{bp} ; E R \alpha, 91 \mathrm{bp} ; E R \beta, 110 \mathrm{bp} ; M C 4 R, 90 \mathrm{bp}$; and 18S, $187 \mathrm{bp}$ ) were resolved on ethidium bromide-stained $2 \%$ agarose gels in Tris-acetic acid-EDTA and photographed using a gel documentation system (GeneSnap; Syngene). Inner primer bands were extracted, purified (GeneClean Turbo Kit; MP Biomedicals Australasia), and sequenced (Micromon, Monash University, VIC, Australia) to determine the PCR product base pair sequence.

Statistics and figure preparation. The relative proportions of neurons projecting to retroperitoneal WAT (rWAT) and/or subcutaneous (inguinal) WAT (iWAT) and immunohistochemical data, represented as the mean percentage of total PRV-positive neurons, were transformed for analysis using the arcsin transformation (Sokal and Rohlf, 1969; Pompolo et al., 2006). Data that did not fit a normal distribution determined by the Shapiro-Wilk test for normality $(p<0.05)$ and/or violated the homogeneity of variance assumption determined by the Levene's test of equality of variances $(p<0.05)$ were analyzed using nonparametric statistics. Statistical tests were performed using PASW (SPSS) Statistics 19.0 to determine the differences within and between the sexes. The LCM data were analyzed using a $\chi^{2}$ test. All other data were analyzed using a three-way mixed ANOVA with Bonferroni's post hoc tests, two-way independent ANOVA with Bonferroni post hoc tests, or Mann-Whitney $U$ test for independent-measures analysis of two groups.

Sections were analyzed and photographed with a fluorescent microscope and a built-in digital camera (Imager.Z1; Zeiss). The only elements of the photographs modified were brightness and contrast using AxioVi- 
Table 2. Numbers of neurons positive for candidate transmitters and receptors expressed as a percentage of total laser captured PRV-labeled neurons

\begin{tabular}{|c|c|c|c|c|c|c|c|}
\hline & $\mathrm{ER} \alpha$ & $\mathrm{ER} \beta$ & CART & NPY & Insulin receptor & $\mathrm{ObRb}$ & MC4R \\
\hline \multicolumn{8}{|l|}{ Female } \\
\hline Subcutaneous ( $n=13$ cells) & $38.46^{*}$ & 7.69 & 38.46 & 7.69 & 23.07 & 38.46 & 15.38 \\
\hline Abdominal ( $n=28$ cells $)$ & $39.29^{*}$ & 0.00 & 50.00 & 10.71 & 39.29 & 28.57 & 17.86 \\
\hline \multicolumn{8}{|l|}{ Male } \\
\hline Subcutaneous ( $n=17$ cells) & 5.88 & 5.88 & 35.29 & 0.00 & 41.18 & 52.94 & 29.41 \\
\hline Abdominal ( $n=20$ cells) & 25.00 & 10.00 & 40.00 & 5.26 & 50.00 & 40.00 & $5.00^{*}$ \\
\hline
\end{tabular}

${ }^{*} p<0.05$ compared to male neurons projecting to subcutaneous WAT.

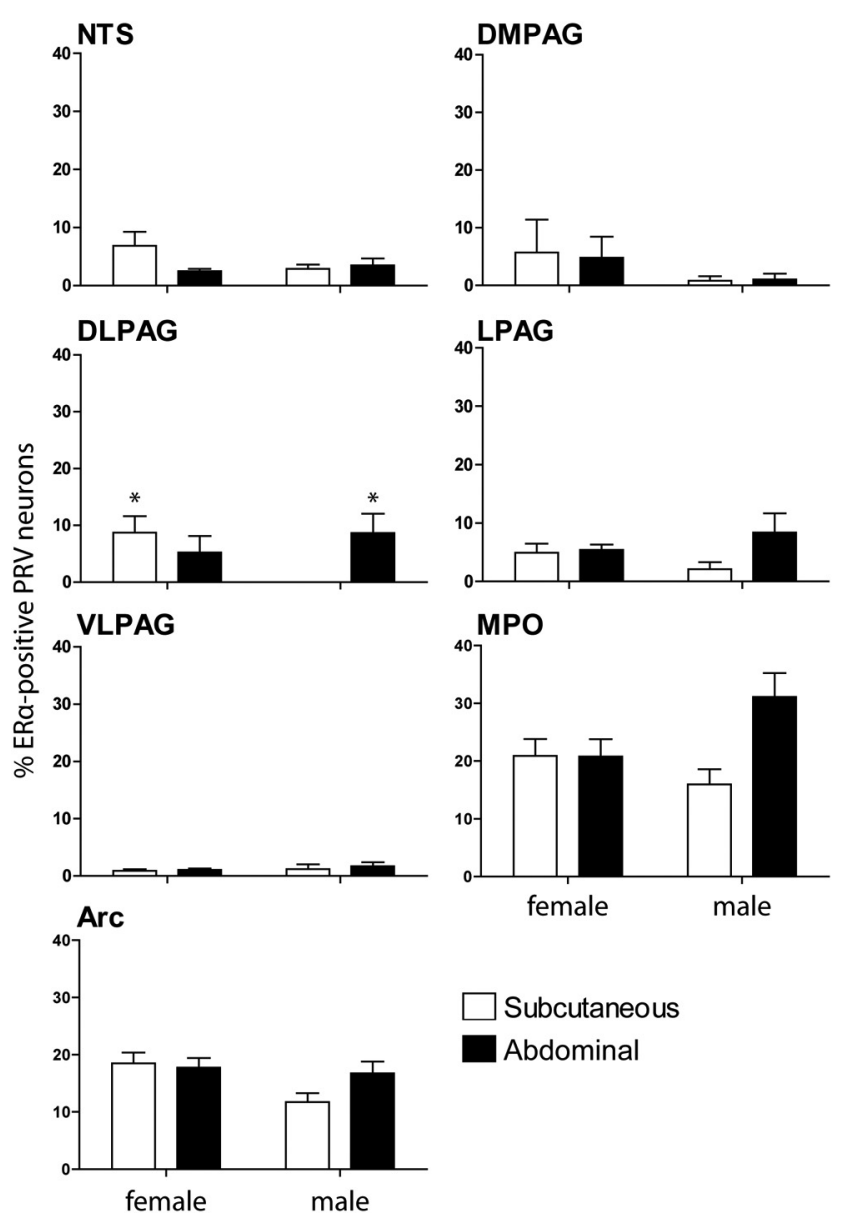

Figure 3. The percentage of PRV-positive neurons projecting to abdominal or subcutaneous WAT depots that also contained estrogen receptor- $\alpha$ in the forebrain and brainstem of male ( $n=11)$ and female $(n=15)$ rats allowed to survive for $5 \mathrm{~d} .{ }^{*} p<0.05$ compared to male neurons projecting to the subcutaneous fat depot.

sionLE 4.5 (2002) and Microsoft Office Picture Manager (2003). Figures were compiled using Adobe Illustrator CS5 (version 15.0.2) and GraphPad Prism 5 (version 5.04).

\section{Results}

Injections of PRV, made into the WAT on the right side of the body, resulted in bilateral labeling of neurons within the forebrain and brainstem. Moreover, the specific virus, defined by the fluorescent reporter, could be varied without effect on the pattern of labeling. The distribution of PRV labeling was consistent between rats, as a mosaic pattern of neurons projecting exclusively to iWAT or rWAT as well as those projecting to both depots, but the numbers of virally infected neurons projecting to either of the depots differed. With survival of $3 \mathrm{~d}$ after injection, spinal nuclei were moderately labeled with little or no hindbrain and forebrain labeling, whereas spinal nuclei were heavily labeled, and hindbrain and forebrain nuclei were moderately labeled after 4-5 d.

Only the spinal cord exhibits regionally specific projections to WAT depots

PRV-labeled neurons were identified predominantly ipsilaterally to the injected WAT in the spinal cord, with some neurons projecting to iWAT or rWAT and some to both depots being identified in the lateral edge of the gray matter in the lateral horn or the intermediolateral nucleus (Fig. $1 A, B) 3 \mathrm{~d}$ after inoculation. A small number of neurons projecting to rWAT were observed in the intermediolateral nucleus contralateral to the side of the injection. The segmental distribution of neurons projecting to the rWAT was between thoracic segment 1 (T1) and T12, whereas neurons projecting to iWAT were located more caudally, concentrated between T8 and T10. Neurons projecting to both fat depots were located between $\mathrm{T} 7$ and T10. In addition to the labeling in the lateral horns of the gray matter, neurons projecting to fat were also identified in more medially positioned groups of sympathetic preganglionic neurons in the spinal cord.

Within the brainstem and midbrain, neurons, $4 \mathrm{~d}$ after inoculation (i.e., premotor to spinal sympathetic outflows), were consistently identified in the rostral ventromedial medulla, locus ceruleus, subceruleus, majority of reticular nuclei, midline raphe (Fig. 1C,D), and rostral ventrolateral midbrain, with a small number in the RVLM. Small numbers of neurons were found in the NTS and area postrema $5 \mathrm{~d}$ after inoculation. Additional neurons were identified in the lateral and medial parabrachial nuclei and PAG in heavily infected brains $5 \mathrm{~d}$ after inoculation.

Within the hypothalamus $4 \mathrm{~d}$ after inoculation, neurons were consistently identified in the LH, PeF, RCh, PVN (Fig. 1E, F), MPO (Fig. $1 G, H$ ), dorsomedial nucleus, and posterior hypothalamic area. Five days after inoculation, neurons were also consistently identified in the arcuate nucleus (Fig. $1 I, J$ ), suprachiasmatic nucleus, lateral preoptic area, and periventricular nucleus, with a small number in the anterior hypothalamic area and ventromedial nucleus from heavily infected brains. In extrahypothalamic forebrain and cortical areas 4-5 d after inoculation, neurons were consistently identified in the amygdala, zona incerta, bed nucleus of the stria terminalis, organum vasculosum of the lamina terminalis, subfornical organ, primary motor cortex, and insular cortex in the most heavily infected brains.

Neurons projecting to rWAT were more prominent in males Male rats had a relatively small proportion of hypothalamic projections specifically to iWAT, with a greater proportion of neurons that projected either to rWAT or both depots. This was evident in the NTS, RVLM, midline raphe, and all forebrain regions analyzed. In contrast, female rats had a decreased proportion of neurons to rWAT and increased proportion of neurons projecting to both fat depots or selectively to iWAT. This was most evident in the PVN, RVLM, raphe pallidus and magnus, 

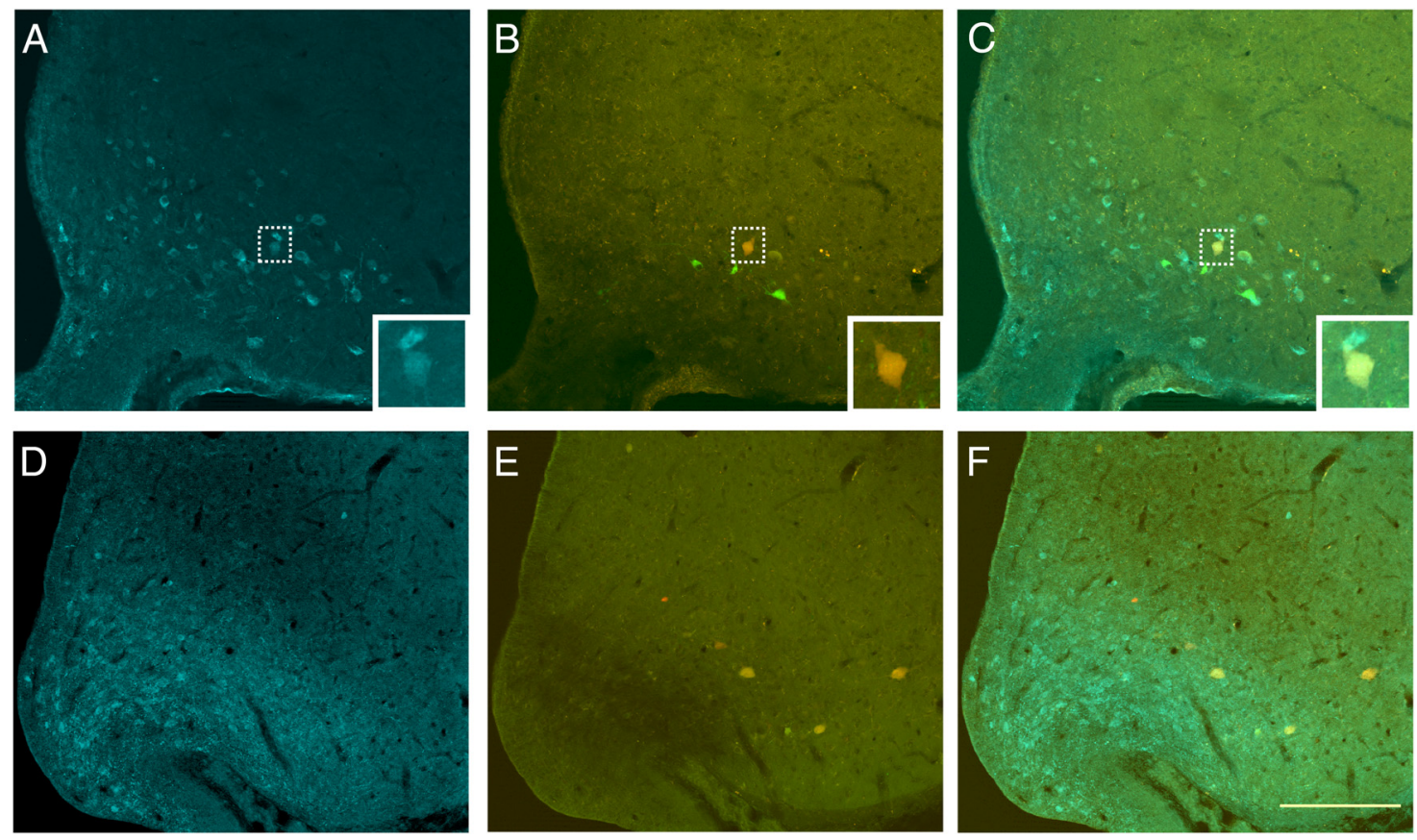

Figure 4. $A-F$, Photomicrographs illustrating the colocalization of agouti-related protein $(\boldsymbol{D}, \boldsymbol{F}$; blue) or $\gamma$-melanocyte stimulating hormone $(\boldsymbol{A}, \boldsymbol{C}$; blue) and neurons projecting polysynaptically to abdominal $(\boldsymbol{B}, \boldsymbol{C}, \boldsymbol{E}, \boldsymbol{F} ;$ green), subcutaneous $(\boldsymbol{B}, \boldsymbol{C}, \boldsymbol{E}, \boldsymbol{F}$; red), or both WAT depots $(\boldsymbol{B}, \boldsymbol{C}, \boldsymbol{E}, \boldsymbol{F}$; yellow) in rats allowed to survive for $5 \mathrm{~d}$ and treated with colchicine for $16 \mathrm{~h}$. PRV-positive neurons projecting to subcutaneous and/or abdominal WAT were not colocalized with AgRP-positive neurons in the arcuate $(\boldsymbol{F})$, but neurons projecting to WAT depots were found to contain $\gamma$-MSH (top insets). Scale bar: (in F) $\boldsymbol{A}-\boldsymbol{F}, 200 \mu \mathrm{m}$; inset, $10 \mu \mathrm{m}$.

ventrolateral periaqueductal gray, lateral hypothalamus, and perifornical region (Fig. 2). Regardless of sex, fewer neurons project specifically to iWAT than to rWAT in all regions analyzed $(p<0.05)$. In the forebrain, a three-way mixed ANOVA revealed a projection type effect $\left(F_{(2,21)}=34.69, p<.001\right)$, projection type by sex interaction effect $\left(F_{(2,21)}=5.57, p<0.05\right)$, and region by projection type interaction effect $\left(F_{(10,105)}=4.06, p<.001\right)$. In the hindbrain, a three-way mixed ANOVA revealed a projection type effect $\left(F_{(2,18)}=17.03, p<.001\right)$, projection type by sex interaction effect $\left(F_{(2,18)}=3.90, p<0.05\right)$, and region by projection type interaction effect $\left(F_{(16,144)}=7.90, p<.001\right)$.

\section{$\mathrm{ER} \alpha$-positive projections to WAT varied in males and} between the sexes

Male rats had a smaller percentage of arcuate neurons projecting to iWAT that expressed $E R \alpha$ than female rats, as illustrated by PCR (Table 2). Immunohistochemical colocalization in the arcuate nucleus demonstrated the same trend, but these data were not statistically significant unless less stringent post hoc tests (Fischer's LSD tests) were used ( $p>0.05 ;$ Fig. 3 ). In the forebrain, a three-way mixed ANOVA revealed a projection type by sex interaction effect $\left(F_{(1,22)}=5.61, p<0.05\right)$.

Male rats also had a lack of ER $\alpha$-positive neurons in the dorsolateral PAG that projected to iWAT compared to females ( $p<$ 0.05 ), instead with a predominance of $\mathrm{ER} \alpha$-positive neurons that projected to rWAT ( $p<0.05$; Fig. 3 ). In the hindbrain, a threeway mixed ANOVA revealed a sex effect $\left(F_{(1,9)}=5.094, p=0.05\right)$ and projection type by sex interaction effect $\left(F_{(1,9)}=5.38, p<\right.$ 0.05 ).

Strong ER $\alpha$ staining not colocalized with PRV-positive neurons was also observed in the caudal ventrolateral ventromedial nucleus of the hypothalamus, bed nucleus of the stria terminalis, amygdala, and spinal trigeminal nucleus. Light $\mathrm{ER} \alpha$ staining was observed in the LH and caudoventrolateral reticular nucleus.
Predominance of catabolic peptide-containing neurons in the arcuate that project to WAT

Regardless of sex, a substantial percentage of Arc neurons that projected to either WAT depot were colocalized with immunohistochemically identified $\gamma$-MSH, a marker of catabolic proopiomelanocortin (POMC) neurons (Fig. 4; $33.48 \pm 10.6$ in females and $39.51 \pm 3.8 \mathrm{in}$ males). In contrast, there was a distinct lack of Arc neurons that projected to either WAT depot colocalized with anabolic AgRP. Consistent with these data, using PCR, $\sim 41 \%$ of laser-captured Arc neurons projecting to either WAT depot expressed catabolic CART, whereas only $4 \%$ expressed anabolic NPY (Table 2).

\section{Sex differences in colocalization of ORX and MCH with neurons that project to WAT}

Female rats had a tendency to have a greater proportion of LH/ PeF neurons that projected to iWAT colocalized with ORX compared to neurons projecting to rWAT (Fig. $5 ; p>0.05$ ). In contrast, female rats had a greater percentage of $\mathrm{LH} / \mathrm{PeF}$ neurons that projected to rWAT and iWAT colocalized with $\mathrm{MCH}$ compared to neurons projecting to rWAT in male rats (Fig. $5 ; p \leq$ 0.05). Analysis of $\mathrm{MCH}$ colocalization using a two-way ANOVA revealed a sex effect $\left(F_{(1,10)}=8.88, p<0.05\right)$.

\section{Sex differences in the pattern of genes expressed in} laser-captured Arc neurons projecting to WAT

Overall, a relatively high percentage of neurons expressed $E R \alpha$, $C A R T, O b R b$, and $I R$, whereas $M C 4 R$ was expressed more moderately, and NPY and $E R \beta$ were present in comparatively low numbers of neurons (Table 2). As noted above, female rats had a greater percentage of laser-captured Arc neurons projecting to iWAT that expressed $E R \alpha$ compared to male rats $(p<0.05$; Table 2 ). In addition, male rats had a smaller number of laser-captured 

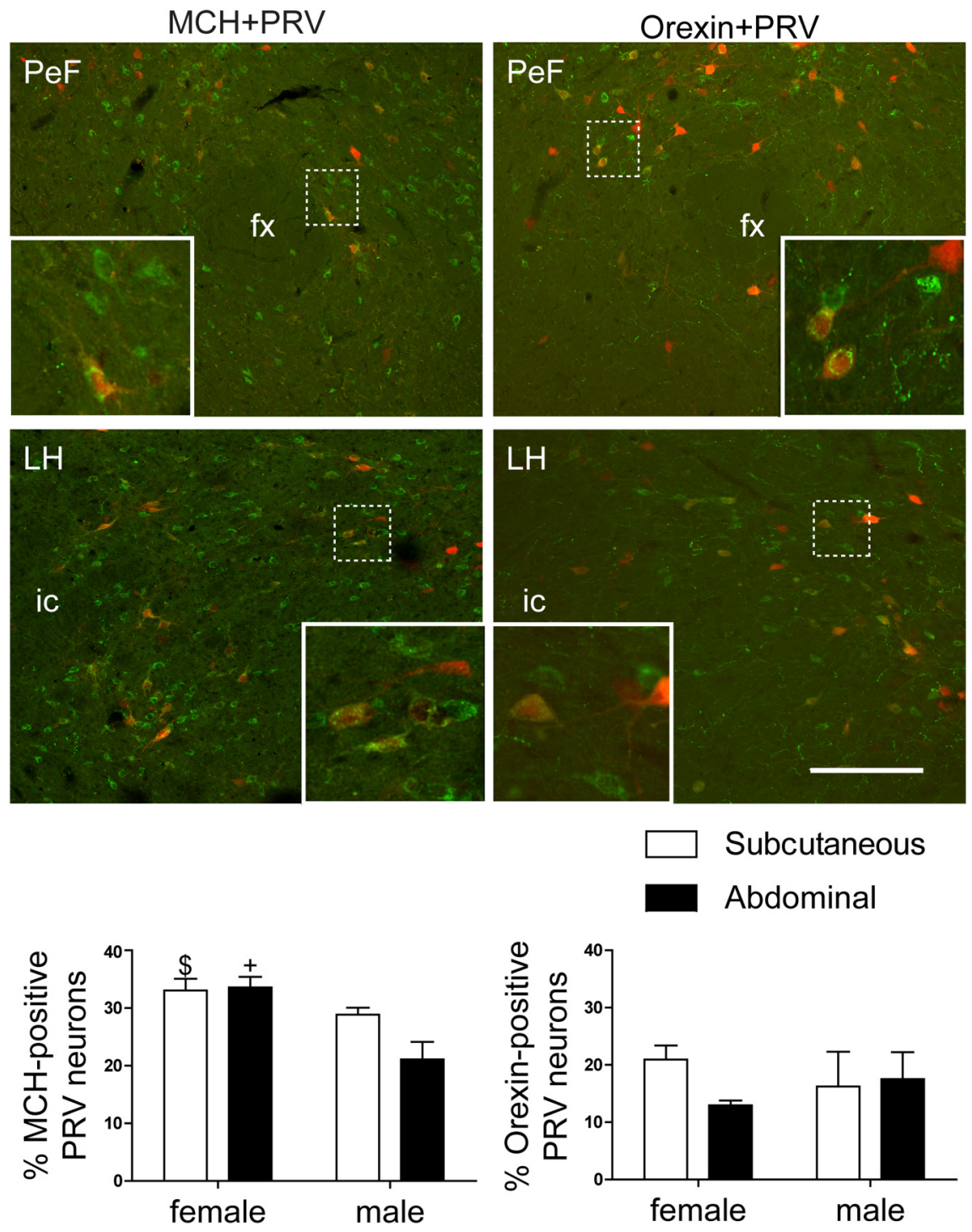

Figure 5. Photomicrographs and bar graphs illustrating the colocalization of MCH (left; green) or orexin-A (right; green) and neurons projecting polysynaptically to WAT depots (left and right; red) in rats ( $n=6$ females; $n=8$ males) allowed to survive for 5 d. PRV-positive neurons projecting to WAT were colocalized with both MCH and orexin-A in the perifornical region (top; insets) and lateral hypothalamus (bottom; insets). fx, Fornix; ic, internal capsule. Scale bar: $200 \mu \mathrm{m}$; inset, $20 \mu \mathrm{m} .{ }^{+} p=0.05$ compared to male neurons projecting to the abdominal fat depot; ${ }^{\$} p=0.051$ compared to male neurons projecting to the abdominal fat depot.

Table 3. The percentage of neurons expressing secondary genes (top row) with respect to the primary genes (left column) that are present in neurons projecting to either fat depot in the arcuate nucleus, regardless of sex

\begin{tabular}{lrrrrrrr}
\hline Secondary genes & & & & & & & \\
\hline & MC4R & \multicolumn{1}{c}{ ObRb } & \multicolumn{1}{c}{$\mathbb{R}$} & NPY & CART & ER $\alpha$ & ER $\beta$ \\
\hline Primary genes & & & & & & & \\
$\quad$ MC4R & & 22.58 & 22.58 & 0.00 & 15.15 & 4.55 & 25.00 \\
ObRb & 53.85 & & 32.26 & 40.00 & 39.39 & 40.91 & 50.00 \\
$\mathbb{I R}$ & 53.85 & 33.33 & & 20.00 & 54.55 & 27.27 & 25.00 \\
NPY & 0.00 & 6.67 & 3.23 & & 0.00 & 13.64 & 0.00 \\
CART & 38.46 & 43.33 & 58.06 & 0.00 & & 40.91 & 50.00 \\
ER $\alpha$ & 7.69 & 30.00 & 19.35 & 60.00 & 27.27 & & 25.00 \\
ER $\beta$ & 7.69 & 6.67 & 3.23 & 0.00 & 6.06 & 4.55 & \\
\hline
\end{tabular}

arcuate neurons projecting to rWAT expressing MC4R $(p<$ $0.05)$.

A large percentage of neurons projecting to WAT expressing the primary genes analyzed (Table 3 ) also expressed leptin recep-
Subcutaneous

tor and CART. ER $\alpha$ was also observed in a moderate to large number of leptin recptor-, NPY-, and CART-positive neurons projecting to WAT, whereas insulin receptor was observed in a moderate to large number of MC4R-, leptin receptor-, $C A R T$ - and $E R \alpha$-positive neurons projecting to WAT. On the other hand, NPY and $E R \beta$ were not often observed to be coexpressed in other neurons projecting to WAT, consistent with the small number of $N P Y$ - and $E R \beta$-expressing neurons projecting to WAT (Table 3 ).

\section{Discussion}

The data generated in this study capitalize on the use of two isogenic strains of an attenuated form of PRV (Bartha) injected into abdominal and subcutaneous fat depots in the same animal. The identical transport properties of viruses that differ only in the nature of their fluorescent reporters circumvents many of the potential problems associated with previous studies that involved either the same virus injected into different animals (Bamshad et al., 1998) or different viruses injected into the same animal (Kreier et al., 2002). The approach adopted here revealed a mosaic pattern of virally labeled neurons in nuclei extending from the spinal cord through the brain stem to the hypothalamus. This mosaic consisted of direct "private lines" to individual fat pads as well as neurons supporting collateral axonal branches to both depots. The latter is in keeping with the concept of "command neurons," a term coined to describe neurons throughout the neuraxis that allow a coordinated, global activation of different organs (Jansen et al., 1995; Oldfield et al., 2007). This heterogeneity of central drivers of sympathetic outflows to fat provides substrates that could underpin both specific and general control of lipolytic activity.

The pattern of WAT-projecting neurons in male and female rats, while not different at the regional level, did exhibit differences in the relative weighting of projections to each WAT depot. In this respect, males had more projections to abdominal fat depots, whereas females exhibited stronger projections to subcutaneous fat, both selectively and via collateral branches. While there was no discernable unique neurochemical signature of these pathways, there was evidence of differential expression of candidate transmitters and receptors. Most prominent among these was $\mathrm{ER} \alpha$, which was preferentially associated with neurons in the hypothalamus and periaqueductal gray projecting multisynaptically to abdominal rather than subcutaneous WAT in males. Further neurochemical localization revealed that leptin and insulin receptors were highly coexpressed in arcuate neurons projecting to WAT (both iWAT and rWAT). Typically such neurons expressed catabolic peptides, $\gamma$-MSH, and CART with little, if any, alignment with the more medially placed anabolic NPY/ 
AgRP arcuate neurons. Anabolic peptides (MCH and ORX) were represented in the LHA/PeF projections to both types of fat.

These findings considerably extend those of previous studies that have sought to establish whether or not there is a differential innervation of abdominal and subcutaneous fat (Bamshad et al., 1998; Song et al., 2005; Kreier et al., 2006). This has clear functional and clinical implications given the differing contributions of the two types of fat to the etiology of metabolic syndrome. Abdominal fat is well recognized for its association with the adverse sequelae of obesity, whereas subcutaneous fat is relatively benign (Park et al., 2003). Previous reports have indicated that the innervation of abdominal WAT is generally greater than that to subcutaneous WAT (Shi et al., 2009). In our hands, neurons projecting exclusively to iWAT were the least abundant in male rats, but this difference disappeared in a number of brain nuclei in female rats, consistent with a sexual dimorphism in the innervation of fat at the cellular level.

We and others have proposed that the ability to differentially modulate the distribution of fat via the nervous system will most likely be reflected in differences in neurochemical content and receptor distribution in fat-directed neurons throughout the neuraxis (Bamshad et al., 1998). While the expression of $\mathrm{ER} \alpha$, evaluated by histochemical and molecular analyses, is not unique to neurons projecting to one fat depot or the other, this receptor was preferentially associated with neurons directed to the abdominal WAT depot in males. It has been proposed that estrogen's actions to reduce body weight and shift fat distribution are mediated via the sympathetic innervations to particular fat depots (Lazzarini and Wade, 1991; Clegg et al., 2006). This is thought to be primarily mediated by $\mathrm{ER} \alpha$ rather than $\mathrm{ER} \beta$ (Heine et al., 2000; Roesch, 2006). The current data using laser capture microdissection and multiplex-nested PCR confirmed that $E R \alpha$ is by far the predominant estrogen receptor in neuronal pathways to WAT.

Colocalization of ER $\alpha$ immunoreactivity and PRV labeling following injections into fat showed double-labeled neurons most prominently in the arcuate nucleus and the NTS, which are often described as hubs for the integration of peripherally derived markers of nutrient availability and subsequent activation of feeding and energy expenditure pathways. (Ricardo and Koh, 1978; Seeley et al., 2004; Grill, 2006). However, such neurons were also present in the PAG and MPO. In fact, the greatest degree of colocalization between PRV neurons and ER $\alpha$ was in the MPO (31 $\pm 4 \%)$. This nucleus has been shown to be involved in the modulation of lipid mobilization and energy expenditure, independent of food intake (Coimbra and Migliorini, 1988; Bagnasco et al., 2002).

The question arises as to what may be the functional significance of a preferential association of $\mathrm{ER} \alpha$ with neurons directed to the abdominal WAT depot in males. If a primary function of estrogen on central neurons is to reduce body weight and body fat mass (Lazzarini and Wade, 1991), it stands to reason that the relatively low circulating levels of estrogen in males would leave the neural pathways to rWAT essentially "understimulated," consistent with an over representation of rWAT in males. However it should be remembered that estrogen is by no means ineffective in regulating body weight in males (Heine et al., 2000; Jones et al., 2000; Maffei et al., 2004). Testosterone is converted to estrogen in males via the aromatase enzyme, which is expressed in many tissues including adipose tissue and brain (Harada et al., 1993). This enzyme is regionally expressed in brain regions such as the medial preoptic area and estrogen acts locally (Zhao et al., 2007). Regardless of the underlying mechanisms that come into play, the preferential association of $\mathrm{ER} \alpha$ with neurons projecting multisynaptically to rWAT is consistent with the observation that introduction of exogenous estrogen into the CNS dramatically reduces rWAT in males (Clegg et al., 2006).

Leptin and insulin receptors were found to be expressed on neurons to WAT, consistent with a direct central role of nutrient/ adiposity-related signals in the regulation of fat pad size and more generally of sympathetic tone (Harris et al., 1998; Clegg et al., 2006; Penn et al., 2006). Moreover, when it is considered that these receptor types were also well colocalized with $E R \alpha$ in neurons of the arcuate nucleus projecting to WAT, a structural substrate begins to emerge that supports the notion that gonadal steroids can regulate body fat distribution via an integrated action with leptin and insulin. In fact, it has been suggested that this occurs through $\mathrm{ER} \alpha$-mediated shifts in hypothalamic sensitivity to leptin and insulin (Clegg et al., 2006). While Clegg et al. (2006) were unable to comment on the regional basis of these pathways because of the intracerebroventricular nature of their infusions, others have reported a colocalization of $\mathrm{ER} \alpha$ and leptin receptors in neurons across a range of preoptic and hypothalamic nuclei including the arcuate nucleus (Diano et al., 1998). In addition to their well-defined roles in mediating energy balance, POMC/ CART neurons in the arcuate nucleus are recognized as headwaters of descending sympathetic pathways (Elias et al., 1998). The present data derived from single-cell PCR show that neurons projecting to WAT coexpress genes coding for leptin, insulin, and $E R \alpha$ as well as the catabolic peptide CART, but rarely are these receptor types associated with NPY-containing neurons projecting to WAT. Double immunohistochemical analysis supports these findings and adds complementary evidence that WATprojecting neurons in the arcuate nucleus preferentially express POMC, the precursor of the catabolic peptide $\alpha-\mathrm{MSH}$, but not AgRP. These data are consistent with those generated from injections of PRV into epididymal WAT in both POMC- and NPYGFP-expressing transgenic mice, where there is a similar alignment of fat-projecting neurons with POMC, but not NPY neurons in the arcuate nucleus (Stanley et al., 2010). The trend to involve catabolic pathways in the innervation of white fat is also evident in studies in hamsters where there is extensive association of the MC4R, the receptor to $\alpha$-MSH, with virus-labeled neurons after inoculation of the subcutaneous fat (Song et al., 2005). In this regard, central infusions of an MC4 receptor antagonist eliminated leptin-induced increases in sympathetic activity (Haynes et al., 1999), and stimulating this system increased sympathetic activity and decreased WAT size (Haynes et al., 1999; Raposinho et al., 2003).

In conclusion, while not defining a unique neurochemical signature of neurons directed to abdominal or subcutaneous fat at any level of the neuroaxis, the present study has elucidated important differences in gene expression in neurons to the two fat beds and has expanded on important differences between sexes in the nature of the innervations of fat. The latter are clearly relevant to an understanding of differential lipolytic actions mediated by descending autonomic pathways to different fat depots. These data are necessary to develop a more complete view of the role of the nervous system in the determination of fat distribution between the sexes and in different hormonal settings within the same sex.

\section{References}

Bagnasco M, Dube MG, Kalra PS, Kalra SP (2002) Evidence for the existence of distinct central appetite, energy expenditure, and ghrelin stimulation pathways as revealed by hypothalamic site-specific leptin gene therapy. Endocrinology 143:4409-4421.

Bamshad M, Aoki VT, Adkison MG, Warren WS, Bartness TJ (1998) Central nervous system origins of the sympathetic nervous system outflow to white adipose tissue. Am J Physiol 275:R291-R299. 
Banfield BW, Kaufman JD, Randall JA, Pickard GE (2003) Development of pseudorabies virus strains expressing red fluorescent proteins: new tools for multisynaptic labeling applications. J Virol 77:10106-10112.

Bartness TJ, Song CK (2007) Sympathetic and sensory innervation of white adipose tissue. J Lipid Res 48:1655-1672.

Bartness TJ, Hamilton JM, Wade GN, Goldman BD (1989) Regional differences in fat pad responses to short days in Siberian hamsters. Am J Physiol 257:R1533-R1540.

Billington CJ, Briggs JE, Grace M, Levine AS (1991) Effects of intracerebroventricular injection of neuropeptide $\mathrm{Y}$ on energy metabolism. Am J Physiol 260:R321-R327.

Brito MN, Brito NA, Baro DJ, Song CK, Bartness TJ (2007) Differential activation of the sympathetic innervation of adipose tissues by melanocortin receptor stimulation. Endocrinology 148:5339-5347.

Clegg DJ, Brown LM, Woods SC, Benoit SC (2006) Gonadal hormones determine sensitivity to central leptin and insulin. Diabetes 55:978-987.

Coimbra CC, Migliorini RH (1988) Cold-induced free fatty-acid mobilization is impaired in rats with lesions in the preoptic area. Neurosci Lett $88: 1-5$.

Diano S, Kalra SP, Sakamoto H, Horvath TL (1998) Leptin receptors in estrogen receptor-containing neurons of the female rat hypothalamus. Brain Res 812:256-259.

Elias CF, Lee C, Kelly J, Aschkenasi C, Ahima RS, Couceyro PR, Kuhar MJ, Saper CB, Elmquist JK (1998) Leptin activates hypothalamic CART neurons projecting to the spinal cord. Neuron 21:1375-1385.

Gambacciani M, Ciaponi M, Cappagli B, De Simone L, Orlandi R, Genazzani AR (2001) Prospective evaluation of body weight and body fat distribution in early postmenopausal women with and without hormonal replacement therapy. Maturitas 39:125-132.

Grattan DR, Jasoni CL, Liu X, Anderson GM, Herbison AE (2007) Prolactin regulation of gonadotropin-releasing hormone neurons to suppress luteinizing hormone secretion in mice. Endocrinology 148:4344-4351.

Grill HJ (2006) Distributed neural control of energy balance: contributions from hindbrain and hypothalamus. Obesity (Silver Spring) 14 [Suppl 5]: 216S-221S.

Harada N, Utsumi T, Takagi Y (1993) Tissue-specific expression of the human aromatase cytochrome P-450 gene by alternative use of multiple exons 1 and promoters, and switching of tissue-specific exons 1 in carcinogenesis. Proc Natl Acad Sci U S A 90:11312-11316.

Harris RB, Zhou J, Redmann SM Jr, Smagin GN, Smith SR, Rodgers E, Zachwieja JJ (1998) A leptin dose-response study in obese (ob/ob) and lean $(+/$ ?) mice. Endocrinology 139:8-19.

Haynes WG, Morgan DA, Djalali A, Sivitz WI, Mark AL (1999) Interactions between the melanocortin system and leptin in control of sympathetic nerve traffic. Hypertension 33:542-547.

Heine PA, Taylor JA, Iwamoto GA, Lubahn DB, Cooke PS (2000) Increased adipose tissue in male and female estrogen receptor-alpha knockout mice. Proc Natl Acad Sci U S A 97:12729-12734.

Jansen AS, Nguyen XV, Karpitskiy V, Mettenleiter TC, Loewy AD (1995) Central command neurons of the sympathetic nervous system: basis of the fight-or-flight response. Science 270:644-646.

Jones ME, Thorburn AW, Britt KL, Hewitt KN, Wreford NG, Proietto J, Oz OK, Leury BJ, Robertson KM, Yao S, Simpson ER (2000) Aromatasedeficient $($ ArKO) mice have a phenotype of increased adiposity. Proc Natl Acad Sci U S A 97:12735-12740.

Kotani K, Tokunaga K, Fujioka S, Kobatake T, Keno Y, Yoshida S, Shimomura I, Tarui S, Matsuzawa Y (1994) Sexual dimorphism of age-related changes in whole-body fat distribution in the obese. Int J Obes Relat Metab Disord 18:207-212.

Kreier F, Fliers E, Voshol PJ, Van Eden CG, Havekes LM, Kalsbeek A, Van Heijningen CL, Sluiter AA, Mettenleiter TC, Romijn JA, Sauerwein HP, Buijs RM (2002) Selective parasympathetic innervation of subcutaneous and intra-abdominal fat-functional implications. J Clin Invest 110:1243-1250.

Kreier F, Kap YS, Mettenleiter TC, van Heijningen C, van der Vliet J, Kalsbeek A, Sauerwein HP, Fliers E, Romijn JA, Buijs RM (2006) Tracing from fat tissue, liver, and pancreas: a neuroanatomical framework for the role of the brain in type 2 diabetes. Endocrinology 147:1140-1147.

Lazzarini SJ, Wade GN (1991) Role of sympathetic nerves in effects of estradiol on rat white adipose tissue. Am J Physiol 260:R47-R51.

Ludwig DS, Tritos NA, Mastaitis JW, Kulkarni R, Kokkotou E, Elmquist J,
Lowell B, Flier JS, Maratos-Flier E (2001) Melanin-concentrating hormone overexpression in transgenic mice leads to obesity and insulin resistance. J Clin Invest 107:379-386.

Maffei L, Murata Y, Rochira V, Tubert G, Aranda C, Vazquez M, Clyne CD, Davis S, Simpson ER, Carani C (2004) Dysmetabolic syndrome in a man with a novel mutation of the aromatase gene: effects of testosterone, alendronate, and estradiol treatment. J Clin Endocrinol Metab 89:61-70.

Oldfield BJ, Allen AM, Davern P, Giles ME, Owens NC (2007) Lateral hypothalamic 'command neurons' with axonal projections to regions involved in both feeding and thermogenesis. Eur J Neurosci 25:2404-2412.

Park YW, Zhu S, Palaniappan L, Heshka S, Carnethon MR, Heymsfield SB (2003) The metabolic syndrome: prevalence and associated risk factor findings in the US population from the Third National Health and Nutrition Examination Survey, 1988-1994. Arch Intern Med 163:427-436.

Paxinos G, Watson C (1998) The rat brain in stereotaxic coordinates, Ed 4. London: Academic.

Penn DM, Jordan LC, Kelso EW, Davenport JE, Harris RB (2006) Effects of central or peripheral leptin administration on norepinephrine turnover in defined fat depots. Am J Physiol Regul Integr Comp Physiol 291:R1613-R1621.

Pompolo S, Pereira A, Estrada KM, Clarke IJ (2006) Colocalization of kisspeptin and gonadotropin-releasing hormone in the ovine brain. Endocrinology 147:804-810.

Quennell JH, Mulligan AC, Tups A, Liu X, Phipps SJ, Kemp CJ, Herbison AE, GrattanDR,AndersonGM (2009) Leptinindirectlyregulatesgonadotropinreleasing hormone neuronal function. Endocrinology 150:2805-2812.

Raposinho PD, White RB, Aubert ML (2003) The melanocortin agonist Melanotan-II reduces the orexigenic and adipogenic effects of neuropeptide Y (NPY) but does not affect the NPY-driven suppressive effects on the gonadotropic and somatotropic axes in the male rat. J Neuroendocrinol 15:173-181.

Ricardo JA, Koh ET (1978) Anatomical evidence of direct projections from the nucleus of the solitary tract to hypothalamus, amygdala and other forebrain structures in rat. Brain Res 153:1-26.

Roesch DM (2006) Effects of selective estrogen receptor agonists on food intake and body weight gain in rats. Physiol Behav 87:39-44.

Seeley RJ, Drazen DL, Clegg DJ (2004) The critical role of the melanocortin system in the control of energy balance. Annu Rev Nutr 24:133-149.

Shi H, Bartness TJ (2001) Neurochemical phenotype of sympathetic nervous system outflow from brain to white fat. Brain Res Bull 54:375-385.

Shi H, Seeley RJ, Clegg DJ (2009) Sexual differences in the control of energy homeostasis. Front Neuroendocrinol 30:396-404.

Smith BN, Banfield BW, Smeraski CA, Wilcox CL, Dudek FE, Enquist LW, Pickard GE (2000) Pseudorabies virus expressing enhanced green fluorescent protein: A tool for in vitro electrophysiological analysis of transsynaptically labeled neurons in identified central nervous system circuits. Proc Natl Acad Sci U S A 97:9264-9269.

Sokal RR, Rohlf FJ (1969) Biometry; the principles and practice of statistics in biological research San Francisco: W. H. Freeman.

Song CK, Jackson RM, Harris RB, Richard D, Bartness TJ (2005) Melanocortin-4 receptor mRNA is expressed in sympathetic nervous system outflow neurons to white adipose tissue. Am J Physiol Regul Integr Comp Physiol 289:R1467-R1476.

Stanley S, Pinto S, Segal J, Pérez CA, Viale A, DeFalco J, Cai X, Heisler LK, Friedman JM (2010) Identification of neuronal subpopulations that project from hypothalamus to both liver and adipose tissue polysynaptically. Proc Natl Acad Sci U S A 107:7024-7029.

Tchernof A, Desmeules A, Richard C, Laberge P, Daris M, Mailloux J, Rhéaume C, Dupont P (2004) Ovarian hormone status and abdominal visceral adipose tissue metabolism. J Clin Endocrinol Metab 89:3425-3430.

Tritos NA, Maratos-Flier E (1999) Two important systems in energy homeostasis: melanocortins and melanin-concentrating hormone. Neuropeptides 33:339-349.

Tsuneki H, Wada T, Sasaoka T (2010) Role of orexin in the regulation of glucose homeostasis. Acta Physiol (Oxf) 198:335-348.

Youngstrom TG, Bartness TJ (1995) Catecholaminergic innervation of white adipose tissue in Siberian hamsters. Am J Physiol 268:R744-R751.

Zhao C, Fujinaga R, Tanaka M, Yanai A, Nakahama K, Shinoda K (2007) Region-specific expression and sex-steroidal regulation on aromatase and its mRNA in the male rat brain: immunohistochemical and in situ hybridization analyses. J Comp Neurol 500:557-573. 